\title{
A Dollars and "Sense" Exploration of Vape Shop Spending and E-cigarette Use
}

\author{
Sears C. ${ }^{1,}$ Hart J.' Wolker K.', Lee A. ${ }^{1,}$ Keith R.' Ridner S. ${ }^{1}$
}

\begin{abstract}
INTRODUCTION Across the US, vape shops have emerged to provide e-cigarette users access to products not usually available at gas stations or retail stores. As vape shop sales have steadily increased, so have questions about the impact of marketing and price on e-cigarette use behaviors. In this exploratory analysis, we aim to characterize spending on e-cigarettes and evaluate the association with customer perceptions and use behaviors.

METHODS In a cross-sectional survey of vape shop customers $(n=78)$, perceptions and use of e-cigarettes and tobacco products were assessed. Descriptive statistics and multivariate logistic regression were used to evaluate the association between spending and socioeconomic factors, demographics, and use behaviors.

RESULTS Overall, spending amounts ranged from less than $\$ 10 /$ month to more than $\$ 250 /$ month, with a median around $\$ 50-75 /$ month. Males spent more than females ( $p=0.003)$, but spending did not significantly differ by age $(\mathrm{p}=0.13)$. Customers who spent more than $\$ 50 / \mathrm{month}$ used lower levels of nicotine $(\mathrm{mg} / \mathrm{ml})(\mathrm{p}=0.003)$ but a greater quantity of e-liquid $(\mathrm{ml} / \mathrm{month})$ $(\mathrm{p}<0.0001)$ compared to customers who spent under that amount. Mod use and intention to use e-cigarettes as a cessation device were significantly associated with vape shop spending in the regression model $(\mathrm{OR}=17.5 ; 95 \% \mathrm{CI}=(4.3,70.2)$ and $\mathrm{OR}=0.22 ; 95 \% \mathrm{CI}=(0.06,0.75)$, respectively).

concLusions Spending appears to be significantly associated with e-cigarette use behaviors. Making "sense" of the potential relationships between the dollars spent at vape shops and consumer use behaviors is important as regulations for e-cigarette sales are proposed.
\end{abstract}

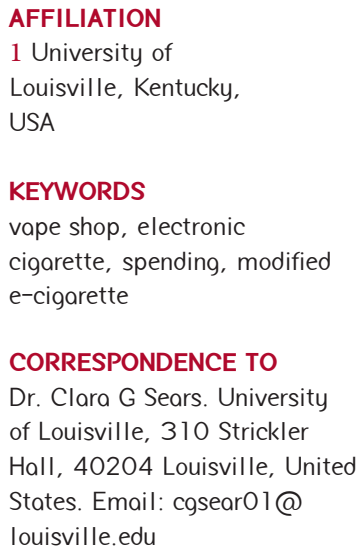

\section{INTRODUCTION}

Decades of research surrounding use of traditional forms of tobacco provided a well-informed knowledge base for health care providers and policy makers to develop interventions for tobacco control ${ }^{1-3}$. The advent of electronic cigarettes (e-cigarettes) and vape shops (specialty retail stores for e-cigarettes and supplies) has opened a new front in the marketing and regulation of nicotine delivery. By evaluating vape shop spending, we can begin to identify specific demographics and consumer behaviors that may be targeted via marketers' unique reinvention of old tobacco promotion techniques as well as useful in developing policy regulation or health interventions.
While large e-cigarette manufacturing companies ("big vape") have been able to aggressively pursue customers by increasing marketing expenditure across media channels ${ }^{4}$, vape shops have more restrictive budgets and are forced to implement creative, low-cost advertising methods ${ }^{5}$. With marketing of e-cigarettes unregulated, vape shops have resorted to advertising techniques initially used by tobacco companies. Examples of these techniques include use of coupons, giveaways, and special sales to bring in new customers ${ }^{5}$. In addition, vape shops also advertise at community and social events, as well as host events, like vape competitions and concerts, to build a strong sense of community among the customer base $\mathrm{b}^{5}$. Exposure to e-cigarette use and products 
through recreational and social events may shape people's perceptions of the products and reasons for using them.

Beyond marketing in the community, exposure to e-cigarette use and products also occurs once a customer is inside a vape store. Vape retailers design stores to encourage customers to "hang out" by including bars, sofas, and beverage services ${ }^{5,}$ ${ }^{6}$. Vape shops provide customers with a wide selection of products and e-liquid flavors. Newer generations of e-cigarettes commonly sold in vape shops are far more advanced than earlier generation and disposable e-cigarettes ${ }^{7}$. First generation e-cigarettes were designed to resemble traditional cigarettes and consisted of a basic pre-filled compartment with e-liquid, an aerosol generator, a flow sensor, and battery. Newer generations incorporate larger refillable e-liquid tanks and allow the user to modify performance and design to preference. For example, modified e-cigarettes (mods) allow the user to adapt voltage and resistance to produce the preferred amount of vapor and flavor ${ }^{8}$.

At many vape shops, customers can sample different flavors, select from a wide array of e-liquids, and receive assistance adjusting their mods. In addition to these services, employees mix flavors to create unique combinations for the customer ${ }^{6}$, ${ }^{7}$. Customers appreciate the choices and added value ${ }^{9}$. In an analysis of vape shop Yelp reviews, the most mentioned store feature was the variety of e-liquid flavors and selection of e-cigarette hardware ( $95.2 \%$ of reviews), with only $32 \%$ of reviewers describing vape shops as a place to help with smoking cessation. These reviews may provide insight into customers' expectations and reasons for visiting vape shops ${ }^{9}$.

The architectural design of vape shops, which tends to encourage customers to linger and relax, and their promotion of customizable products through social events suggest the targeting of customers who are hobbyist vapors rather than simply individuals trying to use e-cigarettes as a cessation device $^{5,6,9}$. Recreational promotion of e-cigarettes is concerning given these devices could be a new (and novel) pathway to nicotine addiction, especially for adolescents ${ }^{10,11}$. For example, studies indicate that both use and exposure to advertising have increased drastically in the last few years (e.g., use among adolescents and adults nearly tripled; advertising exposure increased $254 \%$ among adolescents and $321 \%$ among young adults ${ }^{12-14}$. These findings are consistent among adolescents, college students, and young adults ${ }^{15}$.

The purpose of the current research is to explore vape shop spending among e-cigarette users to characterize the target customer base. Specifically, we aim to 1) evaluate the relationship between spending on nicotine delivery devices prior to and after vaping initiation and 2) characterize spending by e-cigarette and tobacco use and socioeconomic and demographic factors.

\section{METHOD}

\section{Data Collection}

The Electronic Cigarette Opinion Survey (ECOS), a crosssectional questionnaire, was administered in nine vape shops located in Louisville, Kentucky. Vape shops were selected across four quadrants in the city to capture broad customer demographics. ECOS is a 39-item questionnaire that took approximately 10 minutes for participants to complete. The investigator generated questionnaire collected information about demographic characteristics, e-cigarette use behaviors, and current and past tobacco use. Tobacco use questions were adapted from the CDC National Adult Tobacco Survey (NATS) Questionnaire to capture days and frequency of e-cigarette use behaviors ${ }^{16}$.

The ECOS questionnaire was administered during afternoon and evening business hours on weekends to maximize customer traffic in vape shops. Vape shop customers and employees, 18 years and older, were invited to participate by research team personnel. Participants completed the questionnaire while in the vape shop and did not receive an incentive for participation. The Institutional Review Board of the University of Louisville approved all procedures.

\section{Participants}

Overall, the study consisted of 80 participants. Two participants were excluded from this analysis due to being first-time users $(n=78)$. The majority $(75.3 \%)$ of participants were male ( $n$ $=58)$ with $24.7 \%$ female $(\mathrm{n}=19$; one person did not specify gender), and the median age was 27.8 years (range $=18.2$ 58.8). Most participants had no college degree (2-year, 4-year, or professional) (72.4\%), were employed for wages $(83.3 \%)$, and had a household income of $\$ 50,000$ or more (62.3\%).

\section{Measures and Definitions \\ Socioeconomic Status (SES)}

Highest education level, annual household income, and employment status were assessed as measures of SES. Highest education level was reported as: high school graduate, GED, vocational school, some college, 2-year college degree, 4-year college degree, or professional degree. Due to the small sample size, the variable was dichotomized into high school graduate, GED, vocational school, or some college (No college degree) and 2-year college degree, 4-year college degree, or professional degree (College degree) for use in statistical analysis. Household income was reported as a categorical 
variable: $\$ 14,999$ per year or less, $\$ 15,000-\$ 24,999, \$ 25,000$ $\$ 34,999, \quad \$ 35,000-\$ 49,999, \quad \$ 50,000-\$ 74,999, \quad \$ 75,000-$ $\$ 99,999, \$ 100,000-\$ 149,999, \$ 150,000$ or more. For analysis, the variable was dichotomized at the median into less than $\$ 50,000$ and $\$ 50,000$ or more, which also reflects the median household income in Louisville, KY. Employment status was classified into two categories: individuals who were employed for wages and those who were not.

\section{E-cigarette and Nicotine Use}

The amount of e-liquid used (milliliters/day) in a vape pen or mod multiplied by the frequency of use (days/month) was used to quantify e-cigarette use ( $\mathrm{ml} / \mathrm{month})$. The nicotine level of the e-liquid (none, low $=1-3 \mathrm{mg} / \mathrm{ml}$, medium $=4-11 \mathrm{mg} / \mathrm{ml}$, high= $12-24 \mathrm{mg} / \mathrm{ml}$ ) was multiplied by the total e-liquid used $(\mathrm{ml} / \mathrm{month})$ to quantify total nicotine ( $\mathrm{mg} / \mathrm{month})$.

\section{Mod Use}

Participants were classified as mod users if they responded "yes" to the question, "Do you mod?".

\section{Traditional Cigarette Use before Voping}

Ever smokers (former or current) were defined as having smoked 100 or more cigarettes in their lifetime. Use of traditional cigarettes was quantified by the number of cigarettes smoked per day before e-cigarette use initiation multiplied by the number of days used per month (every day $=30$ days, some days $=15$ days, not at all $=0$ days) to obtain the number of cigarettes smoked per month, which was converted into packs/ month (given 20 cigarettes $=1$ pack). Current use of traditional tobacco was defined as using "some days" or "every day" in the past month.

\section{Spending on Cigarettes}

Monthly spending on cigarettes was estimated based on the quantity of cigarettes smoked prior to vaping initiation and the average cost of a pack of cigarettes in Kentucky, \$4.86.

\section{Intention to Use E-cigarettes for Tobacco Cessation}

Intention to use e-cigarettes for tobacco cessation was assessed by the question, "What is the main reason that you tried e-cigarettes?". Participants who responded "To help me cut back or quit traditional tobacco use" were considered to be primarily using e-cigarettes as a tobacco cessation or reduction method.

\section{Primary Outcome: Monthly Spending on E-cigarettes and Supplies}

Customer spending was assessed by the question, "On average, how much do you spend per month on e-cigs and supplies?". Participants were provided 12 response options in $\$ 25$ intervals ranging from "Less than $\$ 10$ a month" to "More than $\$ 250$ a month". The distribution of the responses was assessed and the variable was dichotomized at the median into low (less than $\$ 50$ a month) and high ( $\$ 50$ a month or more) spending groups.

For the analysis comparing spending on nicotine delivery prior to and after vaping initiation, the average of each interval was used to estimate each participant's spending per month on e-cigarettes and supplies.

\section{Statistical Analysis}

Descriptive techniques were used to characterize demographic factors, socioeconomic status measures, e-cigarette and nicotine use, mod use, and traditional tobacco use among low and high spending customers. Frequency and percentages for discrete variables, as well as mean (SD) and median (range) for continuous variables are summarized and compared between the two spending groups. The distribution of continuous variables was assessed for normality using the Shapiro-Wilk Test. P-values were calculated using Fisher's Exact Test for categorical variables and Wilcoxon Rank-Sum test for continuous variables.

To address our first specific aim, a paired t-test was used to compare spending on nicotine delivery devices and supplies prior to and after vaping initiation. The amount spent at vape shops plus current spending on cigarettes (for dual users only) was compared to the estimated amount the participant was spending on traditional cigarettes prior to vaping.

For our second specific aim, multiple logistic regression models were estimated with spending per person as the dependent variable. Gender, total e-liquid used, nicotine level, use of mods, current tobacco use, and intent to use e-cigarettes as a cessation device were significantly related to spending (p-value $<0.05)$ and therefore considered for inclusion as predictor variables in multiple logistic regression models.

In order to prevent collinearity and overfitting in the model, correlation between the predictor variables was first assessed using the Pearson product-moment correlation coefficient and Spearman's rank correlation coefficient. Mod use was found to be significantly correlated with both nicotine level and quantity of e-liquid used; therefore, including mod use, nicotine level, and quantity of e-liquid as covariates in the model is redundant. Thus, only mod use, and not quantity of e-liquid or nicotine level, was further considered for inclusion as a predictor variable. Next, mod use, gender, current tobacco use, and intent to use e-cigarettes as a cessation device were 
assessed for inclusion as predictor variables in the regression models using forward and backward selection procedures. Predictor variables that were significantly associated with spending ( $p$-value <0.05) and improved the fit of the model (lower AIC) were included in the final regression model. The final regression model included mod use, gender, and intent to use e-cigarettes as a cessation device as covariates. The regression model was applied according to procedures outlined by Agresti ${ }^{17}$.

Odds ratios, p-values and 95\% confidence intervals from the multivariate logistic regression model are reported. An alpha $=5 \%$ was used to declare results statistically significant. Due to the exploratory nature of the study, p-values are not adjusted for multiple comparisons. Statistical software package SAS 9.4 (Cary, N.C.) was used for statistical analysis.

\section{RESULTS}

Overall, spending amounts ranged from less than $\$ 10 /$ month to more than $\$ 250 /$ month, with a median around $\$ 50-75$ / month. Spending was not significantly different by age $(p=0.13)$. The median age in the low spending group (less than $\$ 50$ ) was 29.5 (range= 18.5-58.8) and the median age in the high spending group ( $\$ 50$ or more) was 26.5 (range= 18.2-53.3). The low spending group was 55.9\% (19) male and $42.4 \%$ (14) female while the high spending group was $88.6 \%$ (39) male and $11.4 \%$ (5) female. Significantly more male participants spent $\$ 50$ or more per month than females $(\mathrm{p}=0.003)$.

The descriptive statistics characterizing low and high spenders are reported in Table 1 for categorical variables and Table 2 for continuous variables. There was no significant difference in spending by education level $(\mathrm{p}=0.20)$, annual household income $(\mathrm{p}=0.46)$, or employment status $(\mathrm{p}=1.00)$.

Participants who spent more money per month used significantly more e-liquid $(\mathrm{p}<0.0001)$, but lower levels of nicotine in their e-liquid ( $\mathrm{p}=0.003$ ). However, despite using lower levels of nicotine in e-liquid $(\mathrm{mg} / \mathrm{ml})$, people who spent more money did not have a lower total quantity of nicotine ( $\mathrm{mg} / \mathrm{month})$ compared to low spenders $(\mathrm{p}=0.56)$. The majority (90.9\%) of participants spending over $\$ 50$ a month used mods, which was significantly more than participants spending less than $\$ 50$ a month $(\mathrm{p}<0.0001)$.

Table 1: Descriptive Characteristics of Vape Shop Spending Groups

\begin{tabular}{|c|c|c|c|c|}
\hline & $\begin{array}{l}\text { Low Spending } \\
\qquad n=33\end{array}$ & $\begin{array}{l}\text { Iligh Spending } \\
\qquad n=15\end{array}$ & $\begin{array}{l}\text { Total } \\
n=78\end{array}$ & Pvalue \\
\hline \multicolumn{5}{|l|}{ Education } \\
\hline No college degree & $63.6 \%(21)$ & $79.1 \%(34)$ & $72.4 \%(55)$ & 0.20 \\
\hline College degree & $36.4 \%(12)$ & $20.9 \%(9)$ & $27.6 \%(21)$ & \\
\hline \multicolumn{5}{|l|}{ Annual Household Income 1} \\
\hline Less than $\$ 50,000$ & $43.3 \%(13)$ & $33.3 \%(13)$ & $37.7 \%(26)$ & 0.46 \\
\hline$\$ 50,000$ or more & $56.7 \%(17)$ & $66.7 \%(26)$ & $62.3 \%(43)$ & \\
\hline \multicolumn{5}{|l|}{ Employed for wages } \\
\hline Yes & $84.9 \%(28)$ & $82.2 \%(37)$ & $83.3 \%(65)$ & 1.00 \\
\hline No & $15.2 \%(5)$ & $17.8 \%(8)$ & $16.7 \%(13)$ & \\
\hline Nicotine Level $(\mathrm{mg} / \mathrm{ml})$ & & & & 0.003 \\
\hline None & $12.5 \%(4)$ & $4.4 \%(2)$ & $7.8 \%(6)$ & $0.002 a$ \\
\hline $1-3 \mathrm{mg} / \mathrm{ml}$ & $28.1 \%(9)$ & $66.7 \%(30)$ & $50.7 \%(39)$ & 0.016 \\
\hline $4-11 \mathrm{mg} / \mathrm{ml}$ & $37.5 \%(12)$ & $24.4 \%(11)$ & $29.9 \%(23)$ & $0.05 c$ \\
\hline $12-24 \mathrm{mg} / \mathrm{ml}$ & $21.8 \%(7)$ & $4.4 \%(2)$ & $11.7 \%(9)$ & $0.03 d$ \\
\hline & & & & $0.25 e$ \\
\hline \multicolumn{5}{|l|}{ Use mods } \\
\hline Yes & $43.8 \%(14)$ & $90.9 \%(40)$ & $71.1 \%(54)$ & $<0.0001$ \\
\hline No & $56.3 \%(18)$ & $9.1 \%(4)$ & $28.9 \%(22)$ & \\
\hline \multicolumn{5}{|l|}{ Smoked 100 cigarettes in lifetime } \\
\hline Yes & $97.0 \%(32)$ & $91.1 \%(41)$ & $93.6 \%(73)$ & 0.39 \\
\hline No & $3.0 \%(1)$ & $8.9 \%(4)$ & $6.4 \%(5)$ & \\
\hline \multicolumn{5}{|l|}{ Currently using traditional tobacco } \\
\hline Yes & $25.8 \%(8)$ & $2.3 \%(1)$ & $12.0 \%(9)$ & 0.003 \\
\hline No & $74.2 \%(23)$ & $97.7 \%(43)$ & $88.0 \%(66)$ & \\
\hline \multicolumn{5}{|c|}{ Intent to use e-cigarettes for tobacco cessation } \\
\hline \multicolumn{5}{|c|}{ Yes } \\
\hline No & $66.7 \%(22)$ & $42.2 \%(19)$ & $52.6 \%(41)$ & 0.04 \\
\hline & $33.3 \%(11)$ & $57.8 \%(26)$ & $47.4 \%(37)$ & \\
\hline
\end{tabular}

Spending per month is median split into low and high categories. 1Do not wish to disclose $n=9$

aOverall $p$-value for nicotine levels (excluding none) bP-value for None and 1-3 vs. 4-11 and 12-24 cP-value for None vs. 1-3

dP-value for 1-3 vs. 4-11 eP-value for 4-11 vs. 12-24 
Research Paper

Table 2: E-cigaretteand Tobacco Use by Spending Group

\begin{tabular}{|c|c|c|c|c|}
\hline & $\begin{array}{l}\text { Low Spending } \\
\text { n } 33\end{array}$ & $\begin{array}{c}\text { Iligh Spending } \\
n=15\end{array}$ & $\begin{array}{l}\text { Total } \\
\mathbf{n}=78\end{array}$ & Pvalue \\
\hline \multicolumn{5}{|l|}{ Total e-liquid used (ml/month) } \\
\hline Median (Range) & $73.5(6-600)$ & $150(30-900)$ & $120(6-900)$ & \multirow[t]{2}{*}{$<0.0001$} \\
\hline Mean (SD) & $112.5(126.7)$ & $254.69(218.2)$ & $33(197.1)$ & \\
\hline \multicolumn{5}{|l|}{ Total nicotine (mg/month) } \\
\hline Median (Range) & $450(0-2520)$ & $360(0-4500)$ & $405(0-4500)$ & \multirow[t]{2}{*}{0.56} \\
\hline Mean (SD) & $601.5(636.4)$ & $802.5(1039)$ & $719.0(894.8)$ & \\
\hline \multicolumn{5}{|c|}{ Number of cigarette packs per month before starting to vape } \\
\hline \multirow{3}{*}{$\begin{array}{r}\text { Median (Range) } \\
\text { Mean (SD) }\end{array}$} & & & & \multirow{3}{*}{0.55} \\
\hline & & & & \\
\hline & $23.3(0-53.3)$ & $23.3(0-53.3)$ & $23.3(0-53.3)$ & \\
\hline
\end{tabular}

Spending per month is median split into low and high categories. Non-parametric p-values are provided.

\section{Table 3: Results from Multiple Logistic Regression}

$\begin{array}{lccc} & \text { B Estimate } & \text { Standard Error } & \text { P value } \\ \text { Mod use } & 2.38 & 0.73 & 0.001 \\ \begin{array}{l}\text { Intent to use } \\ \text { e-cigarettes for }\end{array} & -1.82 & 0.70 & 0.009 \\ \text { tobacco cessation } & & & \\ \text { Gender } & 1.62 & 0.78 & 0.04\end{array}$

More low spenders intended to use e-cigarettes as a cessation device $(\mathrm{p}=0.04)$. There was no significant difference between the spending groups in the number of participants that were "ever smokers" ( $p=0.39)$ or the quantity of traditional cigarettes smoked per month before vaping $(\mathrm{p}=0.55)$; however, more participants who spent less money per month on e-cigarettes reported currently using traditional tobacco $(p=0.003)$.

The mean amount of money spent per month on nicotine delivery devices (cigarettes) prior to vaping initiation was $\$ 127.87$ ( $\mathrm{SD}=76.6$ ) whereas the mean spent on nicotine delivery devices (e-cigarettes as well as cigarettes for dual users) after vaping initiation was $\$ 85.99$ ( $\mathrm{SD}=61.8)$. The mean amount spent per month on cigarettes prior to vaping initiation was not significantly different for low and high vape shop spenders (mean=122.74, $\mathrm{SD}=73.54$ and mean $=131.64$, $\mathrm{SD}=79.34$, respectively; $\mathrm{p}=0.55$ ). There was a significant correlation between spending on nicotine delivery devices prior to and after vaping initiation $(\rho=0.27 ; p=0.01)$. Results from the paired t-test indicated that spending on nicotine delivery devices was significantly lower after vaping initiation compared to spending on cigarettes only $(t=4.54, \mathrm{p}=<0.0001)$.

Results from the multivariate logistic regression model (Table 3) demonstrate that spending is significantly associated with gender, mod use, and intention to use e-cigarettes as a cessation device $(\mathrm{AIC}=79.1)$. The odds of participants who used mods spending $\$ 50$ or more per month were about 11 times greater than those who did not use mods $(\mathrm{OR}=10.77$; $95 \% \mathrm{CI}=(2.6,45.3) ; \mathrm{p}=0.001)$, when controlling for gender and intention to use e-cigarettes as a tobacco cessation device. The odds were significantly lower that participants who intended to use e-cigarettes as a tobacco cessation device would spend $\$ 50$ or more per month on e-cigarettes and supplies $(\mathrm{OR}=0.16$; $95 \% \mathrm{CI}=(0.04,0.63) ; \mathrm{p}=0.009)$, while controlling for gender and mod use. The odds of male participants spending $\$ 50$ or more per month were significantly greater compared to females $(\mathrm{OR}=5.07 ; 95 \% \mathrm{CI}=(1.102,23.3) ; \mathrm{p}=0.04)$ when controlling for mod use and intention to use e-cigarettes as a cessation device.

\section{DISCUSSION}

Almost three-fourths of participants used mods, and half of participants indicated the main reason they tried e-cigarettes was for cessation. Mod users were likely to spend more money in vape shops, whereas people who intended to use e-cigarettes as a cessation device were likely to spend less money. In addition, men were found to spend more in vape shops than women. Despite there being no significant difference between high and low spenders in ever smokers and amount of traditional cigarettes smoked before vaping, people who spent less money were currently using traditional cigarettes--suggesting high spending customers may be more successful in tobacco cessation using e-cigarettes.

Spending patterns in our study suggest vape shops may attract customers who initially purchase e-cigarettes for tobacco cessation. Perhaps these customers view the lower cost of e-cigarettes, compared to traditional cigarettes, as a benefit. A recent report by tobacco analysts for Wells Fargo found that e-cigarettes are approximately $8 \%$ cheaper than traditional cigarettes (based on cost per pack ${ }^{18}$. We found, on average, participants' monthly spending on nicotine delivery 
devices decreased $32.3 \%$ after vaping initiation. The amount spent on e-cigarettes includes both e-liquid and supplies, so an average savings per pack cannot be easily estimated. However, our estimate is able to capture the overall savings for the cost of the addiction/habit/hobby (nicotine delivery) that is achieved by switching from cigarettes to e-cigarettes.

A study of U.S. e-cigarette sales in mass retailers, drugs stores, grocery stores, convenience stores and gas stations found increasing the price of e-cigarettes by $10 \%$ was associated with a decrease in sales of both disposable and reusable e-cigarettes by $12 \%$ and $19 \%$, respectively. However, it was also determined that there was significant potential for cross product substitution between different types of e-cigarette devices ${ }^{19}$. Vape shops provide a greater number of alternative products to e-cigarettes and/or cigarettes manufactured by "big tobacco" companies and typically sold in mass retail stores. Thus, the potential for cross product substitution due to pricing is likely much greater in vape shops.

Cross product substitution may differ by demographic characteristics and use behaviors. Cigarette manufacturing companies recognized early on that increases in pricing can impact people of various ages, demographics, and addiction levels differently due to inconsistent price sensitivities ${ }^{20}$. New FDA regulations that differentially impact devices, e-liquid manufacturing, or sales could have varying impacts on small vape shops compared to large e-cigarette manufacturers. In addition, the cost of FDA regulations passed on to customers could impact the variety of users, for example, e-cigarette hobbyists or people using e-cigarettes primarily for cessation, differently, based on the amount people are willing to spend on products.

Some limitations of this study need to be considered. The sample size was small and the results may not be generalizable to all vape shop customers. In an attempt to survey a broad range of demographics, stores were selected throughout the urban area, and not based on highest customer traffic. The emergence of vape shops in Louisville is relatively new compared to larger cities, so there are fewer shops and the customer base is still being established. Because we were able to survey on multiple days, at multiple times, and at multiple locations, we were able to get a good representation of the customers in Louisville, Kentucky. Another limitation is that spending and use (i.e., traditional cigarette and e-cigarette) were self-reported. In order to reduce recall bias, customers were asked about recent spending and product use.

To more fully understand vape shop culture and customers, including their spending and use patterns, much work remains to be done in future research. For example, future investigations could examine the demographics of vapers and their reasons for using e-cigarettes. Additionally, because the vape shop environment and knowledge possessed by staff members are attractive to customers ${ }^{21}$, further study of these influences on customer behavior, such as spending, is warranted. Studies of youth and young adults are vital, as use is burgeoning in these age groups and young adults are especially active in e-cigarette communities, both in person and online. In line with FDA regulation, examining use behaviors is especially important because not all products are created equally; hence, use may be differentially affected by blanket regulations. Further, continued study of the effects of taxation, such as excise taxes, on e-cigarettes may be helpful in mitigating use $\mathrm{e}^{22-25}$.

\section{REFERENCES}

1. Fiore MC, Jaén CR, Baker TB, et al: Treating tobacco use and dependence: 2008 update. Clinical Practice Guideline. Rockville, MD: U.S. Department of Health and Human Services. Public Health Service. May 2008.

2. .S. Department of Health and Human Services: The Health Consequences of Smoking: A Report of the Surgeon General, 2004, U.S. Department of Health and Human Services, Centers for Disease Control and Prevention, National Center for Chronic Disease Prevention and Health Promotion, Office on Smoking and Health: Atlanta.

3. U.S. Department of Health and Human Services: The Health Consequences of Involuntary Exposure to Tobacco Smoke: A Report of the Surgeon General, Center for Disease Control and Prevention, 2006, U.S. Department of Health and Human Services, Coordinating Center for Health Promotion, National Center for Chronic Disease Prevention and Health Promotion, Office on Smoking and Health: Atlanta.

4. Kim AE, Arnold KY, and Makarenko O: E-cigarette advertising expenditures in the U.S., 2011-2012. Am J Prev Med 2014, 46(4):409-12. doi: 10.1016/j.amepre.2013.11.003.

5. Cheney M, Gowin M, and Wann TF: Marketing practices of vapor store owners. Am J Public Health [2015], 105(6):e16-21. doi:10.2105/AJPH.2015.302610.

6. Lee YO, Kim AE: 'Vape Shops' and 'E-Cigarette lounges' open across the USA to promote ENDS. Tobacco Control 2014, Online First.

doi: 10.1136/tobaccocontrol2013-051437.

7. Sussman S, Baezconde-Garbanati L, Garcia R, Barker DC, Samet JM, Leventhal A, and Unger JB: Commentary: Forces that drive the vape shop industry and implications for the health professions. Eval Health Prof [2015].

doi: 10.1177/0163278715586295.

8. Etter JF: Characteristics of users, and usage of different types of electronic cigarettes: findings from an online survey. Addiction 2015 .

doi: 10.1111/add.13240.

9. Sussman S, Garcia R, Cruz TB, Baezconde-Garbanati L, Pentz MA, and Unger BA: Consumers' perceptions of vape shops in Southern California: an analysis of online Yelp reviews. Tobacco Induced Diseases 2014, 12(22):1-9.

doi: 10.1186/s12971-014-0022-7. 


\section{Research Paper}

10. Yuan M, Cross SJ, Loughlin SE, and Leslie FM: Nicotine and the adolescent brain. J Physiol [2015], 593(16):3397-412. doi: 10.1113/JP270492.

11. Schneider S and Diehl K: Vaping as a catalyst for smoking? An initial model on the initiation of electronic cigarette use and the transition to tobacco smoking among adolescents. Nicotine Tob Res 2015. doi:10.1093/ntr/ntv193.

12. Duke JC, Lee YO, Kim AE, Watson KA, Arnold KY, Nonnemaker JM, and Porter L: Exposure to electronic cigarette television advertisements among youth and young adults. Pediatrics 2014, 134(1):e29-36. doi: 10.1542/peds.2014-0269.

13. Corsi DJ and Lippert AM: An examination of the shift in school-level clustering of US adolescent electronic cigarette use and its multilevel correlates, 2011-2013. Health Place 2016, 3830-38. doi: 10.1016/j.healthplace.2015.12.007.

14. King BA, Patel R, Nguyen KH, and Dube, SR: Trends in awareness and use of electronic cigarettes among US adults, 2010-2013. Nicotine Tob Res 2015, 17(2):219-27. doi: $10.1093 / \mathrm{ntr} / \mathrm{ntu} 191$.

15. Carroll Chapman SL and Wu LT: E-cigarette prevalence and correlates of use among adolescents versus adults: a review and comparison. J Psychiatr Res 2014, 5443-54. doi: 10.1016/j.jpsychires.2014.03.005.

16. Centers for Disease Control and Prevention: National Adult Tobacco Survey Questionnaire 2014, retrieved from: http://www. cdc.gov/tobacco/data_statistics/surveys/nats/pdfs/2012-2013questionnaire.pdf.

17. Agresti A: Categorical data analysis, 3rd 2013. J.W. Sons. Hoboken, New Jersey: John Wiley \& Sons.

18. Wieczner J: 10 things e-cigarettes won't tell you. MarketWatch 2013.

19. Huang J, Tauras J, and Chaloupka FJ: The impact of price and tobacco control policies on the demand for electronic nicotine delivery systems. Tob Control 2014, 23 Suppl 3iii41-7. doi: 10.1136/tobaccocontrol-2013-051515.

20. Chaloupka FJ, Cummings KM, Morley CP, and Horan JK: Tax, price and cigarette smoking: evidence from the tobacco documents and implications for tobacco company marketing strategies. Tobacco Control 2002, 11(Suppl1):i62-i72. doi:10.1136/tc.11.suppl_1.i62.

21. Wagener TL, Shaikh RA, Meier E., Tackett AP, Tahirkheli NN, Leavens EL, and Driskill L: Examining the smoking and vaping behaviors and preferences of vape shop customers. Tob Prev Cessation 2016, 2(Suppl 5). doi: https://doi.org/10.18332/tpc/65150

22. Orzechowski W and Walker R: The Tax Burden on Tobacco Historical Compilation [2014]: Arlington, VA.

23. Freiberg M: Options for state and local governments to regulate noncigarette tobacco products. Annals of Health Law 2012, 21(2):407445.

24. Grace RC, Kivell BM, and Laugesen M: Estimating cross-price elasticity of e-cigarettes using a simulated demand procedure. Nicotine Tob Res 2015, 17(5):592-8. doi: $10.1093 / \mathrm{ntr} / \mathrm{ntu} 268$.

25. Stoklosa M, Drope J, and Chaloupka FJ: Prices and e-cigarette demand: Evidence from the European Union. Nicotine Tob Res 2016, 18(10):1973-80.

doi: $10.1093 /$ ntr/ntw109.

ACKNOWLEDGEMENTS

We extend thanks to Allison Siu, Courteney Smith, Aruni Bhatnagar, Rose Marie Robertson, and Anshula Kesh for their support of and contributions to this project.

CONFLICT OF INTERESTS All the authors have completed and submitted the ICMJE Form for Disclosure of Potential Conflicts of Interest and none were reported.

\section{FUNDING}

Research reported in this work was supported by grant number P5OHL120163 from the National Heart, Lung and Blood Institute (NHLBI) and FDA Center for Tobacco Products (CTP). The content is solely the responsibility of the authors and does not necessarily represent the official views of the National Institutes of Health or the Food and Drug Administration.

PROVENANCE AND PEER REVIEW

Commissioned; externally peer reviewed 